\title{
Hepatocellular Carcinoma: Known and Emerging Risk Factors
}

\author{
Daniela Sciancalepore, Maria Teresa Zingaro, Chiara Valentina Luglio, \\ Carlo Sabbà, Nicola Napoli* \\ Clinica Medica “Cesare Frugoni”, Department of Interdisciplinary Medicine, University of Bari “Aldo Moro”, Bari, Italy \\ Email: sciancalepore.daniela@gmail.com, ma.zingaro@tiscali.it,chiarav.luglio@gmail.com, \\ carlo.sabba@uniba.it,*nicola.napoli@uniba.it
}

How to cite this paper: Sciancalepore, D., Zingaro, M.T., Luglio, C.V., Sabbà, C. and Napoli, N. (2018) Hepatocellular Carcinoma: Known and Emerging Risk Factors. Journal of Cancer Therapy, 9, 417-437. https://doi.org/10.4236/jct.2018.95037

Received: March 27, 2018

Accepted: May 21, 2018

Published: May 24, 2018

Copyright $\odot 2018$ by authors and Scientific Research Publishing Inc. This work is licensed under the Creative Commons Attribution International License (CC BY 4.0). http://creativecommons.org/licenses/by/4.0/ Open Access

\begin{abstract}
Hepatocellular carcinoma (HCC) is the most frequent primary liver cancer with a high mortality rate. While chronic hepatitis B virus (HBV) and hepatitis $\mathrm{C}$ virus (HCV) infections represent the leading risk factors worldwide, the spreading of metabolic disorders, such as diabetes, obesity and non-alcoholic fatty liver disease (NAFLD) justifies the increasing attention on their oncogenic mechanisms. This review discusses about the main pathogenic mechanisms implicated in occurrence of HCC in presence of viral and metabolic diseases. Additionally, it points to the importance of clinical surveillance for those patients considered at risk of HCC and highlights the strategical role of serum markers, such as alfa-fetoprotein $(\alpha \mathrm{FP})$ and Protein Induced by Vitamin K Absence or Antagonist II (PIVKA-II), which, in association to a strictly instrumental follow-up, contribute to the early detection of hepatic nodules with a better prognosis for affected patients.
\end{abstract}

\section{Keywords}

Hepatocellular Carcinoma (HCC), Hepatitis B Virus (HBV), Hepatitis C Virus (HCV), Non-Alcoholic Fatty Liver Disease (NAFLD), Non-Alcoholic Steatohepatitis (NASH), Insulin Resistance (IR), Type 2 Diabetes Mellitus (T2DM), Intestinal Microbiota, Visceral Obesity, Alfa-Fetoprotein $(\alpha \mathrm{FP})$, Protein Induced by Vitamin K Absence or Antagonist II (PIVKA-II)

\section{Introduction}

Hepatocellular carcinoma (HCC) generally develops from a background of chronic inflammatory liver disease and, despite both the imminent disappearance of Hepatitis C Virus (HCV)-related chronic disease and the maintenance of a low or absent replication load in Hepatitis B Virus (HBV) chronic infections, 
thanks to new effective antiviral therapies, it represents one of the predominant causes of malignancy-related death worldwide [1]. The leading incidence of HCC in metabolic disorders motivates the clinical approach to the emergent pre-cancerogenic role of non-alcoholic fatty liver disease (NAFLD) and non-alcoholic steatohepatitis (NASH) and justifies the leading scientific interest for the metabolic factors that contribute to their pathogenesis. Moreover, the spreading of metabolic disorders, in addition to known viral risk factors, has required a strictly clinical observation in those patients considered at risk in order to achieve an early diagnosis of HCC.

\section{Epidemiology}

HCC is considered the fifth most common cancer in men and the ninth in the women with a male:female ratio of 2.4 [2]. Moreover, it is the second leading cause of cancer-related death worldwide, preceding lung and stomach cancers [3]. Often, it is diagnosed during the fourth and fifth decades of life with a two times higher incidence among dark-skinned people compared to light-skinned males [4].

HCC distribution is variable worldwide and it has been observed a higher incidence in endemic HBV infection areas, such as sub-Saharan Africa and Eastern Asia (over 20 cases/100.000 population). Conversely intermediate incidence occurs in Mediterranean countries, such as Italy, Greece and Spain, with a rate of 10 - 20 cases $/ 100.000$ population, while North and South America have a relatively low incidence $<5$ per 100.000 individuals [3] [5].

A multitude of etiological risk factors could contribute to the cancerogenesis of HCC. Firstly, hepatotropic viruses, such as HBV, HCV and Hepatitis D Virus (HDV), are strongly associated with the development of HCC, with an increased risk by two to six folds in the HBV/HCV and/or HBV/HDV coinfections. Similarly, alcohol abuse and consumption of aflatoxin B1-contaminated foods are additional risk factors, in association with the emergent role of NAFLD and metabolic syndrome in the incidence of HCC [6] [7] (Figure 1).

\section{HBV}

Despite the emergent role of metabolic syndrome as further risk factor of HCC, HBV infection remains the leading cause for primary hepatic neoplasia with a prevalence of $3.61 \%$ worldwide [8]. As demonstrated by several meta-analysis, the risk of developing HCC is significantly higher (15 - 20 times) in HBV-infected populations compared to uninfected populations [9]. In endemic areas, such as Eastern and African countries, the prevalent HBV transmission is vertical and perinatal and more than $90 \%$ of infected patients become chronic HBV carriers. On the contrary, in low prevalence geographic areas, such as Western countries, the HBV infection is acquired during adulthood through sexual or parental routes and it resolves spontaneously in more than $90 \%$ of cases. 


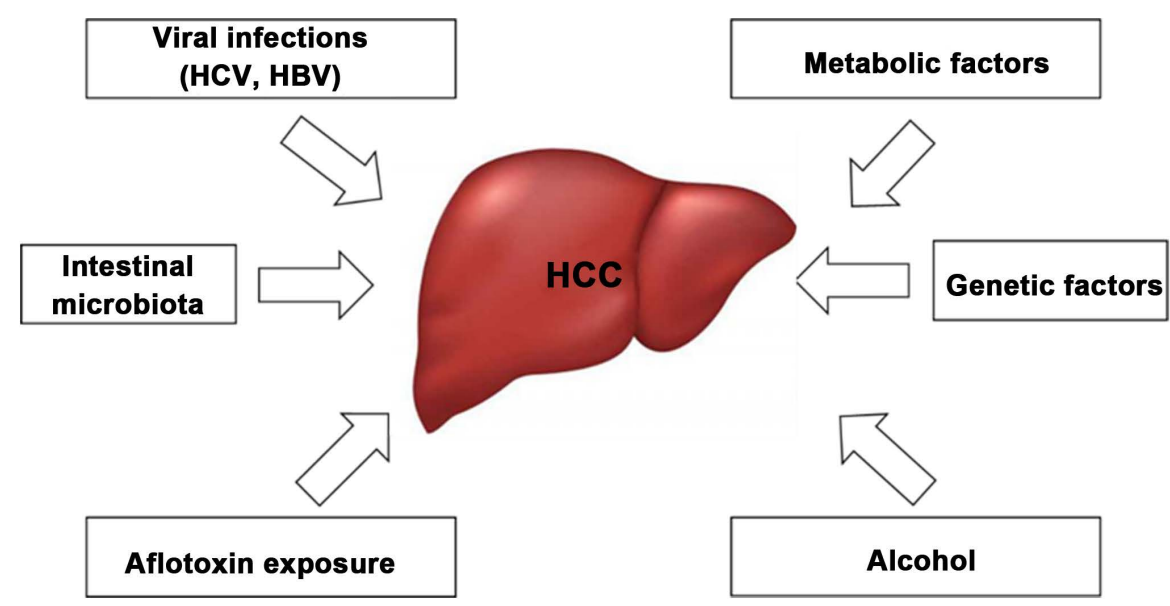

Figure 1. Risk factors for HCC.

It has been reported that annual risk of HCC is $0.5 \%$ and $0.8 \%$ for asymptomatic HBsAg carriers and for patients with chronic HBV disease, respectively; the effective annual risk increases by 100 times for HBV cirrhotic people [5]. Although 70\% - 90\% of HCC occurs in cirrhotic HBV carriers, HBV chronic infection is a well-known cause of HCC also in absence of cirrhosis (Figure 2). The risk of developing hepatocellular carcinoma in patients with persistent HBV infection is greater among males and correlates with the duration of infection, high levels of HBV viral load and infection with genotype "C" of HBV [10]. Co-factors such as family history of HCC, exposure to mycotoxins (aflatoxin), alcohol abuse or tobacco dependence, HCV and/or HDV co-infections, greatly increase the risk of HCC [11] [12].

$\mathrm{HBV}$ is an enveloped virus belonging to the Hepadnaviridae family. Its prevalent hepatotropic behaviour is linked to its capacity of recognizing highly heparin sulfate proteoglycans (HSPGs) on the surface of hepatocytes and, through sodium taurocholate cotransporting polypeptide (NTCP or SLC10A1), HBV colonises infected liver cells [13]. Subsequently, HBV partially double-stranded DNA ( $\mathrm{rcDNA}$ ) becomes a completely circular DNA (ccDNA) into the hepatocyte nucleus and it mimics a template for all HBV proteins [14].

It seems that HBV X protein (HBVx) plays a critical role in the development of HCC activating Wnt/ $\beta$-catenin signalling and promoting tumor initiation through different antiapoptotic mechanisms [15]. First of them, HBVx inhibits p53-mediated apoptosis and it increases the expression of telomerase reverse transcriptase and telomerase activity, thus prolonging the lifespan of hepatocytes and inducing malignant transformation [16]. Additionally, HBVx truncation contributes to the integration of $\mathrm{HBV}$ into the host genome and the c-terminal region produced by its truncation is implicated in the cancerogenesis. As matter of facts, this genomic region induces hepatocytes proliferation, oxidative stress through the production of ROS and it increases the invasiveness and the metastasis HCC-related through the activation of MMP10 by C-Jun signalling [17] [18] [19] [20]. 


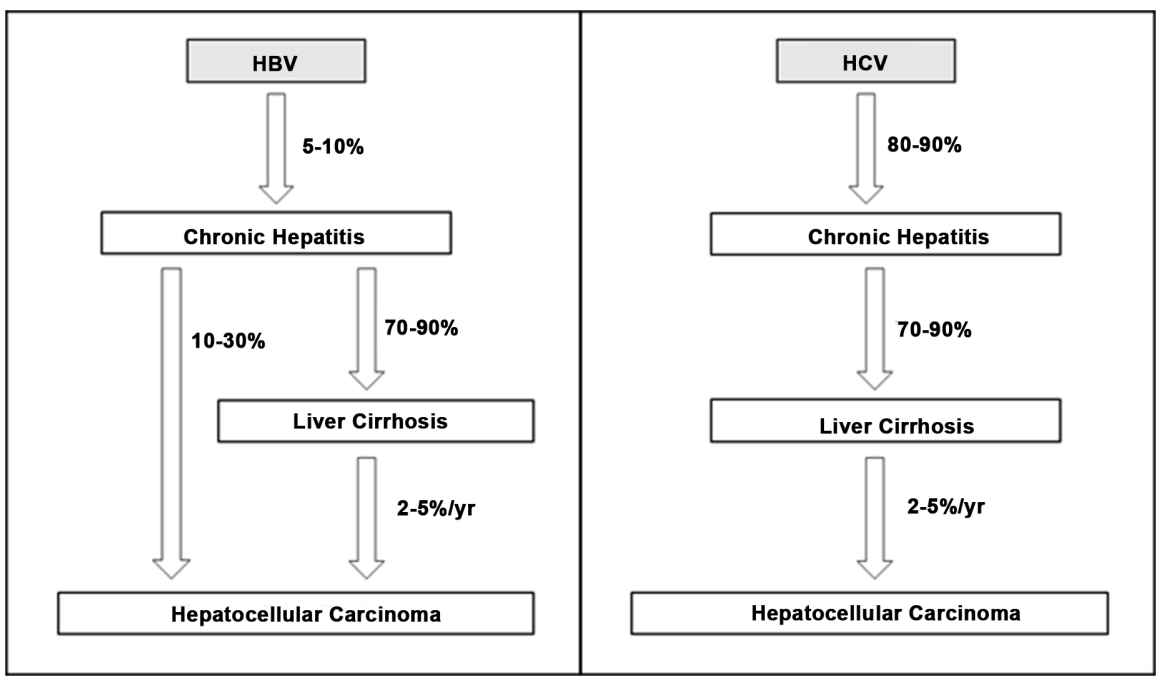

Figure 2. Progression of chronic HBV and HCV infection to HCC.

Small amounts of ccDNA persist in patients with occult HBV infection (e.g. patients $\mathrm{HBsAg}$-negative/anti-HBsAg negative/anti-HBcAg positive) and even in $3 \%-5 \%$ of patients who have cleared HBV infection with seroconversion to anti-HBsAg, This may represent a risk of HBV reactivation with reappearance of HBsAg in subjects with severe immunosuppression, requiring antiviral prophylaxis during immunosuppressive therapies for malignant, inflammatory and autoimmune diseases [21] [22] [23] [24].

Because of this peculiar ability to integrate into the host genome, control of HBV replication by nucleos(t)ide analogues (NAs: entecavir and tenofovir disoproxil), reduces but doesn't eliminate the risk of HCC in patients with persistent HBsAg positivity [25] [26] [27]. Therefore, despite of serum HBV-DNA negativization, a strictly surveillance is recommended in order to achieve an early stage HCC diagnosis.

\section{HCV}

Globally, HCV prevalence has been estimated at 2.5\%, affecting almost 177 million of people worldwide and $10 \%-20 \%$ of HCC diagnosed are HCV infection-related [28]. While HBV infection only chronicizes in 5\% - 10\% of cases, the chronicity of HCV infection occurs in about $85 \%-90 \%$ of patients [29] (Figure 2). In contrast to the Eastern and African countries, where HBV represents the prevalent risk factor for HCC, HCV is considered the leading cause of HCC in developed countries and nowadays the first indication for liver transplantation for HCC in US [30] [31].

$\mathrm{HCV}$, a single-strand RNA virus belonging to the Flaviviridae family, enters human hepatocytes by using cell surface receptors (CD81 and SRB-1) and/or tight junction proteins (Occludin-1 and Claudin) [32] [33] [34]. During replication, HCV genome encodes a polyprotein of about 3000 amino acids which, following a proteolysis, produces the different structural (Envelop E1, E2 and Core) 
and non-structural proteins (P7, NS2, NS3, NS4A, NS4B, NS5A and NS5B) [35]. $\mathrm{HCV}$-induced chronic damage of infected hepatocytes causes the release of pro-inflammatory and fibrotic mediators such as reactive oxygen species and cell death signals [36]. The activation of hepatic stellar cells, predominantly mediated through intracellular inflammasome activation and nuclear receptor family (farsenoid-X-receptor, peroxisome proliferator-activated receptors and others), promotes hepatic inflammation and, consequently, cirrhosis, but also promotes malignant transformation of hepatic infected cells [7] [37] [38]. Several studies demonstrate that core proteins can alter the MAPk pathway, inducing cell proliferation. Moreover, NS5A inhibits p53 protein and, contrasting its antitumoral effects, causes neoplastic degeneration [39]. Furthermore, Platelet-derived growth factor (PDGF) is the most potent mitogenic signal, inducing expression of beta PDGF receptor in stellate cellstogether with other cell surface receptors of growth signaling such as integrins and contributing to fibrogenesis [40]. On the other side, HCV replication stimulates immune defensive response in the host, through the mediation of tumor necrosis factor (TNF- $\alpha$ ) and interferons, results in fibrosis and end stage liver disease. The severity of fibrosis is strictly linked to a higher probability of developing HCC, although different studies highlight the diagnosis of HCC even in low-grade or absence of fibrosis ([41]). Older age at the time of infection, male gender, coinfection with HBV or human immunodeficiency virus (HIV), and metabolic disorders such as obesity, insulin-resistance, diabetes and metabolic syndrome are conditions that significantly increase the risk of developing HCC [42] [43].

The recent introduction of directly acting antivirals (DAAs) allows achieving a sustained virologic response (SVR) in more than $90 \%$ of treated patients, whatever the stage of liver fibrosis. Moreover, the excellent safety profile of DAAs has allowed treatment to a larger number of HCV patients with more advanced liver cirrhosis and a higher risk of HCC [44]. HCV eradication reduces risk of hepatic decompensation and both liver-related and overall mortality, in these subjects [45]. Similarly, the risk of new occurrence and/or recurrence of HCC in patients with advanced liver disfunction or cirrhosis is also significantly reduced but not completely eliminate, despite of HCV infection clearance [46] [47] [48] [49] [50]. Thus, regular surveillance is mandatory amon these patients, even after clinical stabilization and improvement of the fibrosis.

\section{Alcohol}

Alcoholic abuse is considered the oldest risk factor for HCC, particularly in the case of heavy consumption (50 - 70 gr/die) [5]. Furthermore, in the Western developed countries it is considered the leading cause of mortality among people aged between 15 - 49 year [51] [52].

Alcohol is metabolised in acetaldehyde by both alcohol dehydrogenase (at low alcohol concentrations) and CYP2E1 (at higher concentrations), thus it is further metabolised by aldehyde dehydrogenase to acetate. Ethanol's metabolites 
are responsible for the chronic hepatocytes injury; particularly, excessive production of reactive oxygen species (ROS) causes protein, lipid, and DNA oxidation, additionally to a direct cell injury by DNA damage, lipid peroxidation and tumour necrosis factor (TNF) pathway signalling via nuclear factor kappa $B$ [53]. Further mechanisms include iron overload, decreased vitamin A (retinoid acid) levels and downregulation of S-adenosyn-methionine [54].

Although alcohol abuse increases the risk of HCC through the development of fibrosis, there is no evidence that highlights its direct cancerogenic potential. Conversely, different meta-analysis show the synergic actions of alcohol and $\mathrm{HBV}$ and $\mathrm{HCV}$ infection in the process of fibrosis and progression to cirrhosis with a significant higher rate among those patients with a higher consumption [55].

\section{Aflatoxin Exposure}

Aflatoxins are secondary metabolites of Aspergillus flavus and Aspergillus parasiticus, which are fungus that grow under climatic factors, such as high moisture and temperature, typically of Asia and sub-Saharan Africa. Furthermore, they are common contaminants of food, especially in maize, groundnuts, wheat, soy and rice [56].

There are several types of aflatoxin and, according to the International Agency for research on cancer, Aflatoxin B1 (AFB1) is the most toxic and carcinogenic of the family [57]. As matter of fact, while AFB1 is absorbed in the enterocytes of the small intestinal epithelium, liver injury is related to the conversion into aflatoxin-8,9-exo-epoxid thru hepatic cytochrome P450. This metabolite is highly reactive with the $\mathrm{p} 53$ tumor suppressor gene and it generates mutation at codon 249 that has been observed in more than $50 \%$ of HCC cases aflatoxin exposure-related [58] [59]. Subsequently, aflatoxin-8,9-exo-epoxid binds hepatocyte DNA forming procancerogenic adducts that cause further mutations in nucleotides [58].

It has been observed that areas with high prevalence of HCC-aflatoxin related coincide with areas with endemic HBV infection, suggesting a synergic mutagenic role of HBV and AFB1 and justifying the highest risk among those people exposed to both [60] [61] [62].

\section{Metabolic Risk Factors for HCC}

\subsection{NAFLD/NASH}

NAFLD is the most common hepatic disorder in developed countries, with a prevalence ranging from $6 \%$ to $35 \%$ [63]; moreover, it is considered the emerging leading cause of chronic liver disease, with an estimated incidence in Western countries (20\% - 30\%) higher than in Asia (5\% - 18\%) [64]. Additionally, the prevalence of NAFLD is increasing worldwide, depending on the current trends in dietary irresponsibility and preponderance of a sedentary lifestyle and showing a significant linear rise with diabetes and metabolic syndrome [65]. Cur- 
rently, NAFLD represents the second common indication to be listed in liver transplantation and it has been projected that, within the next $10-20$ years, it will become the major cause of liver-related morbidity and mortality, as well as a leading indication for liver transplantation [66].

NAFLD is considered a heterogeneous clinical entity that, starting off the simple hepatic deposition of triglycerides (TG) and steatosis, might evolve to NASH, liver fibrosis, cirrhosis, and eventually hepatocellular carcinoma [65]. Furthermore, it has been observed that progression to cirrhosis or HCC is slower in the presence of NAFLD/NASH than in other chronic liver diseases, occurring in $2.5 \%$ of patients [67]. Additionally, an increased risk of cirrhosis and HCC has been reported in patients with NAFLD and metabolic syndrome (MS)-associated clinical disorders, such as insulin-resistance (IR)/type 2 diabetes mellitus (T2DM), visceral obesity, dyslipidaemia and arterial hypertension [68] [69] [70] [71] [72] (Figure 3).

Liver accumulation of TG represents the direct metabolic consequence of insulin-resistance (IR) and hyperinsulinemia; in fact, IR increases lipoprotein lipase (LpL) activity of adipocytes, with lipolysis and free fat acids (FFA) mobilization through liver, where they are reassembled in TG. Furthermore, hyperinsulinemia reduces microsomal triglyceride transfer protein (MTP) activity, involved in Apo-B secretion, resulting in lower VLDL synthesis and, finally, in a reduced release of TG from the liver [73].

Accumulation of TG in hepatocytes may induce activation of mitochondrial lipoxygenase that increases production of ROS. The alteration of the oxidative state results in micro-inflammation and liver fibrosis [74] [75] [76]. ROS oxygen species induce Kupffer cells (KCs) to produce pro-inflammatory cytokines such as TNF $\alpha$, TGF- $\beta$ and IL- 8 , which are involved in the activation and migration of hepatic stellate cells (HSCs) [77] [78] [79]. HSCs produce lots off collagen fibres resulting in fibrotic state. Under physiological condition, liver injury is rapidly repaired and the fibrotic material (collagen type I, III and IV) is degraded to allow parenchymal tissue regeneration [80]. On the contrary, when the damage persists, the repair mechanisms are continuously activated by depositing, especially in the periportal and perisinusoidal zones, of high amounts of extracellular matrix, predominantly composed by proteoglycans, hyaluronic acid, collagen

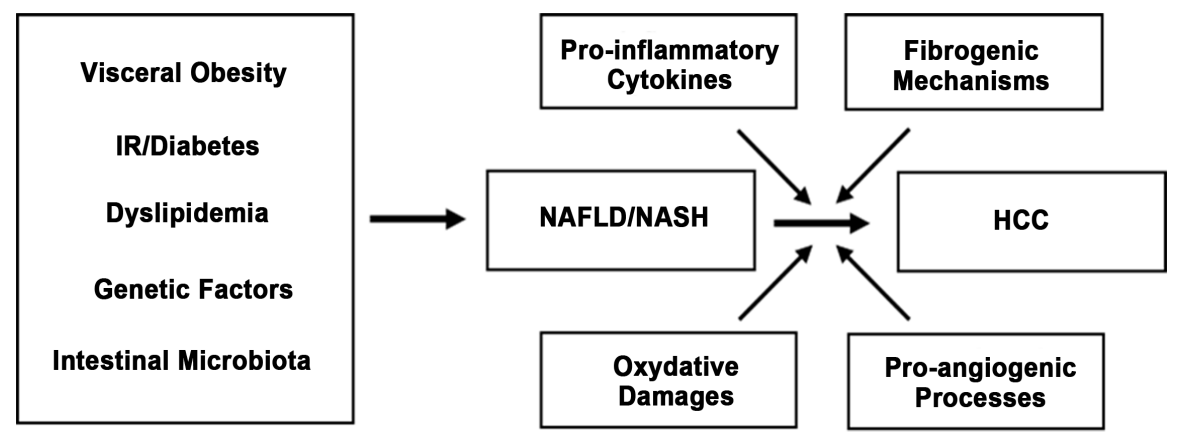

Figure 3. Metabolic Syndrome, NAFLD/NASH and risk of progression to HCC. 
type I and III. This extracellular matrix organizes to form fibrous septa which connect portal areas to one another and often to central areas. Meanwhile, due to the lack of a specific orientation, hepatocytes regenerate by forming nodular structures that do not repeat the typical liver structure [77] [78].

Although HCC usually develops in patients who have progressed to NASH and liver cirrhosis, there are evidences that it may occur in patients with NAFLD in absence of advanced liver fibrosis, making liver steatosis itself a risk factor for HCC. Sanyal et al. reported that the majority of HCC associated with NAFLD/ NASH occur in patients who haven't International Classification of Disease criteria for cirrhosis [81]. Moreover, the risk of developing HCC without cirrhosis is higher in patients with liver steatosis and metabolic syndrome criteria, particularly IR/T2DM and visceral obesity [82].

\subsection{Visceral Obesity}

Epidemiological reports demonstrate that overweight and obesity, two rapidly increasing conditions in developed countries and defined by a body mass index (BMI) higher than 25, significantly correlate with an elevated cancer risk [83] [84]. More than 90,000 cancer-related deaths per year in the US are linked to excessive body weight [85].

Visceral adiposity causes a low grade chronic inflammation with a massive release of pro-inflammatory cytokines. In particular, adipocytes secrete several pro-inflammatory molecules including tumor necrosis factor-alpha (TNF $\alpha$ ) and interleukin-6 (IL-6) which are more clearly linked to the progression from NAFLD to NASH and HCC by stimulating pro-oncogenic signal pathways [84]. TNF $\alpha$ activates c-Jun $\mathrm{NH}_{2}$-terminal kinase (JNK) phosphorylating c-Jun at Ser-63 and Ser-73 by mitogen-activated protein kinases (MAPKs) activity, resulting inapoptosis inhibition and cancerogenesis [86]. Moreover, IL-6 binds to IL-6 receptors (IL-6R) on hepatocytes and liver non-parenchymal cells (biliary epithelial cells and HSCs) to promote binding of the signal-transducing receptor gp130 to the IL-6R complex, thus activating Janus Kinase1 (JAK1). Subsequently, JAK1 activates several intracellular signalling pathways including signal transducer and activator of transcription-3 (STAT3) factor, a known mediator of apoptosis inhibition and cell proliferation [87] [88].

Furthermore, adipose tissue remodelling modifies the hormonal circulation assessment causing adipokines imbalance with increased leptin and decreased adiponectin [87] [89]. It has been showed that leptin is implicated in pro-inflammatory, pro-fibrogenic and pro-angiogenic processes by activating different molecular pathways, such as JAK2/STATs, posphatidylinositide-3-kinases (PI-3Ks)/protein kinase B (Akt) and MAPKs/extracellular regulated kinase 1 and 2 (ERK 1/2). Conversely, adiponectin antagonizes leptin effects with ant-inflammatory, anti-fibrotic, anti-angiogenic and anti-proliferative activities by reducing STAT3 and Akt phosphorylation and by upregulating the expression of suppressor of cytokine signalling (SOCS3) [90] [91]. 


\subsection{IR/T2DM}

Almost $70 \%$ of obese patients affected by T2DM develops NAFLD and almost $30 \%$ of them progress to NASH, highlighting that T2DM increases risk for cirrhosis and HCC [92] [93]. Large population-based cohort studies showed a 1.86 to 4 -fold increase in risk of HCC among patients with diabetes [94].

As already mentioned, IR causes the release of free fatty acids (FFA) towards hepatocytes inducing oxidative stress through overproduction of ROS, cellular inflammation and cancerogenesis. It has been reported that trans-4-hydroxy-2-nonenal, a product of lipid peroxidation, causes mutation of p53 tumor suppressor gene which is associated with more than half of human cancers, including HCC [94].

Hyperinsulinemia IR-induced increases bioavailable insulin-like growth factor-1 (IGF-1) released by hepatocytes because of lower plasmatic concentration of IGF binding proteins. Levels of insulin-like growth factor-2 (IGF-2) are also increased in type 2 diabetic patients; however, IGF-2 is highly expressed in fetal liver and its physiologic function in adult liver remains obscure [95]. The IGF-1 receptor (IGF-1R) is a tyrosine kinase cell-surface receptor that is activated by both IGF-1 and IGF-2, and by insulin with a lower affinity. IGF-1R signalling pathway causes phosphorylation of insulin receptor substrate 1 (IRS-1), a key protein involved in cellular proliferation through phosphatase and tensin homolog (PTEN)/PI-3Ks/Akt and MAPKs cascades.

\section{Microbiota}

Several observations demonstrate that intestinal microbiota (IM) contributes to NAFLD and its status may promote progression to NASH, particularly in obese patients [96] [97].

IM is mainly composed ofat least 500 - 1000 different species and trillions of aerobes and anaerobes microorganisms and, although more than 50 bacterial phyla have been detected, it is dominated by the Bacteroidetes and the Firmicutes [98]. The gut bacteria are able to synthesize vitamins and all essential and nonessential amino acids, contributing to biotransformation of bile [99]. Additionally, they provide the biochemical substrates for the metabolism of host-derivated mucines and nondigestible carbohydrates (large polysaccharides, such as starches, cellulose, hemicellulose, pectins, and gums; some oligosaccharides escaped from digestion; unabsorbed sugars and alcohols from the diet) [100]. These metabolic functions results in the recovery of energy for the host and a supply of energy for the microbiota growth and proliferation. Function and compositionof the IM are influenced by several factors such as age, $\mathrm{pH}$ of the intestinal enviroment, high fat diet and probiotics [101].

Emergent evidences show a strong cross-talk between gut and liver, the so called "gut-liver axis", and it seems that intestinal bacteria are responsible of the maintenance of a healthy axis; furthermore, almost $70 \%$ of liver blood 
derivates from intestine, justifying its role of first line defense against gut-derivated antigens. The findings of NAFLD/NASH as a common complication of both jejuno-ileal bypass surgery for obesity andjejunal diverticulosis, as well as Intestinal Bacterial Overgrowth (IBO), supportthe strictly correlation between NAFLD/NASH and gut-liver axis alterations [102]. In fact, IM-related progression of NAFLD to NASH and HCC depends on increased gut permeability andendotoxin translocation towards liver, inducing the transcriptional activation of a wide variety of proinflammatorygenes and cytokines, suchas TNF-a, and stimulating pro-apoptotic cascades [103] [104]. Additionally, levels of bacterialli popolysaccharide (LPS), a component of theouter membrane of Gram-negative bacteria, are highestin the portal and/or systemic circulation in several types ofchronic liver diseases [105]; LPSbehaves as a hepatotoxin, binds the Kupffer cells toll-like receptor 4 (TLR4) and triggers an intracellular inflammatory cascade that, through the activation of nuclear factor kappa (NF- $\mathrm{kB}$ ), induces the production of proinflammatory cytokines, such as TNF- $\alpha$, IL-1, and IL-6 [106]. Furthermore, TLR4 expressed on hepatic stellate cells (HSCs), mostly implicated in the extracellular matrix deposition, is responsible for the fibrotic process LPS-induced [107].

\section{Polymorphisms}

Emergent evidences show that specific gene polymorphisms are determinant factors for susceptibility and progression of NAFLD. Among them, single-nucleotide polymorphism (SNP) in the patatin-like phospholipase domain-containing protein 3 (PNPLA 3) gene seems to play a key role in TAG remodelling [72]. Asreported by Romeo et al., rs 738409 C > G SNP in the PNPLA3 gene, also called adiponutrin, is significantly associated with NAFLD and it increases the risk of NAFLD-related HCC in European and Japanese populations [108] [109].

PNPLA3, a 481-residue protein, has been identified in various tissues but mostly expressed in the liver, particularly in hepatocytes and hepatic stellate cells, where it explicates hydrolase activity towards triglycerides and retinyl esters, respectively [110]. The cytosine (C) to guanine (G) transversion in rs738409 causes an isoleucine (I) to methionine (M) exchange at amino acid 148 (I148M) with loss of its hydrolysefunction and consequent retention of fat in hepatocytes and retinol in hepatic stellate cells [111] [112]. Additionally, the I148M mutation also reduces very low density lipoproteins (VLDL) secretion and it partially justifies the fat depots in PNPLA3 mutation carriers [113].

Retention of retinoids in hepatic stellate cells results in cell proliferation and differentiation [112] [114] [115]; moreover, the detection of a highest lactate-to-pyruvate ratio in patients with PNPLA3 I148M mutation suggests a shift to anaerobic metabolism probably as a consequence of hepatic hypoxia, mitochondrial dysfunction, and oxidative stress [116]. These pathogenic mechanisms could explain the increased risk of progression to NASH and HCC in patients with Met148 PNPLA3 over expression [117]. 
Table 1. Sensitivity, specificity and predictive value of PIVKA-II and $\alpha \mathrm{FP}$ in the diagnosis of HCC (134).

\begin{tabular}{ccccc}
\hline & Sensitivity & Specificity & PPV & NPV \\
\hline PIVKA-II & $60 \%$ & $88 \%$ & $80 \%$ & $73 \%$ \\
$\alpha$ FP & $67 \%$ & $68 \%$ & $63 \%$ & $72 \%$ \\
PIVKA-II $+\alpha$ FP & $70 \%$ & $94 \%$ & $91 \%$ & $79 \%$ \\
\hline
\end{tabular}

Two other specific gene polymorphisms, such as TM6SF2 E167K and GCKR rs780094, also seem to be associated with a higher risk of fatty liver and liver fibrosis [72]. These evidences underline the role of steatosis as a strong precancerogenic factor that, in association to genetic environment, could contribute to progression to HCC.

\section{Surveillance}

Nowadays, almost $50 \%$ of HCC are diagnosed at advanced stage with a poor prognosis and a 5-year overall survival rate lower than $10 \%$. On the contrary, in patients who receive an earlier diagnosis, the 5-year survival rate increases to 70\% [117]. As suggested by American Association for the Study of Liver (AASLD) and European Association for the Study of Liver (EASL) guidelines for the management of HCC, the implementation of surveillance by a combination of instrumental investigations such as ultrasounds (US), computed tomography (CT) and/or magnetic resonance imaging (MRI), allows to significantly improve the prognosis thanks to the detection of smaller tumors [118] [119]. The availability of serum biomarkers such as alpha-fetoprotein $(\alpha \mathrm{FP})$ and Protein Induced by Vitamin K Absence or Antagonist II (PIVKA-II) in combination with imaging also contributes to improve the accuracy of screening of hepatic malignancies.

The role of $\alpha \mathrm{FP}$ levels in the diagnosis of HCC remains controversial; in fact, despite of elevated $\alpha$ FP levels in 60\% - 80\% of patients with HCC and its usefulness in monitoring of HCC-treated patients, serum $\alpha \mathrm{FP}$ values may be influenced by non-neoplastic factors, such as viral infections and cirrhosis [120] [121] [122]; moreover, low levels of $\alpha \mathrm{FP}$ may be detectable in more than $50 \%$ of HCC patients, highlighting the poor sensitivity of this biomarker [123].

PIVKA-II is considered a suitable serum marker of HCC due to its high specificity. Thanks to the development of accurate measuring methods, Japanese Society Hepatology (JSH) recommends it as a marker of surveillance for HCC [124] [125] [126]. PIVKA-II, also known as des- $\gamma$-carboxy-prothrombin, is an abnormal product of decarboxylation detected in HCC patients, which explicates a mitogenic effect on liver cells, inducing cancerogenesis. Rentao et al. enrolled 2070 PIVKA-II positive patients including 1016 (49.1\%) HCC. Serum levels of PIVKA-II resulted significantly higher in HCC, especially in advanced stage, as compared with no-malignant diseases (including patients with cirrhosis, chronic hepatitis, steatosis, benign nodules, liver abscess, pregnancy) [127]. Furthermore, 
an Italian observational cohort study in patients with US evidence of liver nodules, shows a higher specificity and positive predictive value (PPV) of PIVKA-II as compared to $\alpha \mathrm{FP}$; furthermore, the combined use of PIVKA-II and $\alpha \mathrm{FP}$ improves the diagnostic accuracy as compared to either PIVKA-II or $\alpha$ FPalone (Table 1) [128].

\section{References}

[1] Rahib, L., Smith, B.D., Aizenberg, R., Rosenzweig, A.B., Fleshman, J.M. and Matrisian, L.M. (2014) Projecting Cancer Incidence and Deaths to 2030: The Unexpected Burden of Thyroid, Liver, and Pancreas Cancers in the United States. Cancer Research, 74, 2913-2921. https://doi.org/10.1158/0008-5472.CAN-14-0155

[2] Parkin, D.M., Bray, F., Ferlay, J. and Pisani, P. (2005) Global Cancer Statistics, 2002. CA Cancer Journal of Clinicians, 55, 74-108. https://doi.org/10.3322/canjclin.55.2.74

[3] Ferlay, J., Soerjomataram, I., Dikshit, R., Eser, S., Mathers, C., Rebelo, M., et al. (2015) Cancer Incidence and Mortality Worldwide: Sources, Methods and Major Patterns in GLOBOCAN 2012. International Journal of Cancer, 136, E359-E386. https://doi.org/10.1002/ijc.29210

[4] Mittal, S. and El-Serag, H.B. (2013) Epidemiology of Hepatocellular Carcinoma: Consider the Population. Journal of Clinical Gastroenterology, 47, S2-S6. https://doi.org/10.1097/MCG.0b013e3182872f29

[5] Ozakyol, A. (2017) Global Epidemiology of Hepatocellular Carcinoma (HCC Epidemiology). Journal of Gastrointestinal Cancer, 48, 238-240. https://doi.org/10.1007/s12029-017-9959-0

[6] Donato, F., Tagger, A., Gelatti, U., Parrinello, G., Boffetta, P., Albertini, A., et al. (2002) Alcohol and Hepatocellular Carcinoma: The Effect of Lifetime Intake and Hepatitis Virus Infections in Men and Women. American Journal of Epidemiology, 155, 323-331. https://doi.org/10.1093/aje/155.4.323

[7] Fattovich, G., Stroffolini, T., Zagni, I. and Donato, F. (2004) Hepatocellular Carcinoma in Cirrhosis: Incidence and Risk Factors. Gastroenterology, 127, S35-S50. https://doi.org/10.1053/j.gastro.2004.09.014

[8] Schweitzer, A., Horn, J., Mikolajczyk, R.T., Krause, G. and Ott, J.J. (2015) Estimations of Worldwide Prevalence of Chronic Hepatitis B Virus Infection: A Systematic Review of Data Published between 1965 and 2013. Lancet, 386, 1546-1555. https://doi.org/10.1016/S0140-6736(15)61412-X

[9] Shi, J., Zhu, L., Liu, S. and Xie, W.F. (2005) A Meta-Analysis of Case-Control Studies on the Combined Effect of Hepatitis B and C Virus Infections in Causing Hepatocellular Carcinoma in China. British Journal of Cancer, 92, 607-612. https://doi.org/10.1038/sj.bjc.6602333

[10] Chan, H.L., Tse, C.H., Mo, F., Koh, J., Wong, V.W., Wong, G.L., et al. (2008) High Viral Load and Hepatitis B Virus Subgenotype Ce Are Associated with Increased Risk of Hepatocellular Carcinoma. Journal of Clinical Oncology, 26, 177-182. https://doi.org/10.1200/JCO.2007.13.2043

[11] Chu, Y.J., Yang, H.I., Wu, H.C., Liu, J., Wang, L.Y., Lu, S.N., et al. (2017) Aflatoxin $\mathrm{B}_{1}$ Exposure Increases the Risk of Cirrhosis and Hepatocellular Carcinoma in Chronic Hepatitis B Virus Carriers. International Journal of Cancer, 141, 711-720. https://doi.org/10.1002/ijc.30782

[12] Chen, C.J., Yang, H.I. and Iloeje, U.H. (2009) Hepatitis B Virus DNA Levels and 
Outcomes in Chronic Hepatitis B. Hepatology, 49, S72-S84. https://doi.org/10.1002/hep.22884

[13] Yan, H., Zhong, G., Xu, G., He, W., Jing, Z., Gao, Z., et al. (2012) Sodium Taurocholate Cotransporting Polypeptide Is a Functional Receptor for Human Hepatitis B and D Virus. Elife, 1, e00049. https://doi.org/10.7554/eLife.00049

[14] Zeisel, M.B., Lucifora, J., Mason, W.S., Sureau, C., Beck, J., Levrero, M., et al. (2015) Towards an HBV Cure: State-of-The-Art and Unresolved Questions-Report of the ANRS Workshop on HBV Cure. Gut, 64, 1314-1326. https://doi.org/10.1136/gutjnl-2014-308943

[15] Hsieh, A., Kim, H.S., Lim, S.O., Yu, D.Y. and Jung, G. (2011) Hepatitis B Viral X Protein Interacts with Tumor Suppressor Adenomatous Polyposis Coli to Activate Wnt/Beta-Catenin Signaling. Cancer Letters, 300, 162-172. https://doi.org/10.1016/j.canlet.2010.09.018

[16] Kuo TC, Chao CC. Hepatitis B virus X protein prevents apoptosis of hepatocellular carcinoma cells by upregulating SATB1 and HURP expression. Biochem Pharmacol 2010 Oct 1;80(7):1093-1102.

[17] Jung, S.Y. and Kim, Y.J. (2013) C-Terminal Region of HBx Is Crucial for Mitochondrial DNA Damage. Cancer Letters, 331, 76-83.

https://doi.org/10.1016/j.canlet.2012.12.004

[18] Ching, R.H.H., Sze, K.M.F., Lau, E.Y.T., Chiu, Y.T., Lee, J.M.F., Ng, I.O.L., et al. (2017) C-Terminal Truncated Hepatitis B Virus X Protein Regulates Tumorigenicity, Self-Renewal and Drug Resistance via STAT3/Nanog Signaling Pathway. Oncotarget, 8, 23507-23516. https://doi.org/10.18632/oncotarget.15183

[19] Zhu, R., Mok, M.T., Kang, W., Lau, S.S., Yip, W.K., Chen, Y., et al. (2015) Truncated HBx-Dependent Silencing of GAS2 Promotes Hepatocarcinogenesis through Deregulation of Cell Cycle, Senescence and p53-Mediated Apoptosis. The Journal of Pathology, 237, 38-49. https://doi.org/10.1002/path.4554

[20] Yip, W.K., Cheng, A.S., Zhu, R., Lung, R.W., Tsang, D.P., Lau, S.S., et al. (2011) Carboxyl-Terminal Truncated HBx Regulates a Distinct MicroRNA Transcription Program in Hepatocellular Carcinoma Development. PLoS ONE, 6, e22888. https://doi.org/10.1371/journal.pone.0022888

[21] Bozza, C., Cinausero, M., Iacono, D. and Puglisi, F. (2016) Hepatitis B and Cancer: A Practical Guide for the Oncologist. Critical Reviews in Oncology/Hematology, 98, 137-146.

[22] Pattullo, V. (2016) Prevention of Hepatitis B Reactivation in the Setting of Immunosuppression. Clinical and Molecular Hepatology, 22, 219-237.

https://doi.org/10.3350/cmh.2016.0024

[23] Lok, A.S., Ward, J.W., Perrillo, R.P., McMahon, B.J. and Liang, T.J. (2012) Reactivation of Hepatitis B during Immunosuppressive Therapy: Potentially Fatal Yet Preventable. Annals of Internal Medicine, 156, 743-745. https://doi.org/10.7326/0003-4819-156-10-201205150-00013

[24] Bessone, F. and Dirchwolf, M. (2016) Management of Hepatitis B Reactivation in Immunosuppressed Patients: An Update on Current Recommendations. World Journal of Hepatology, 8, 385-394. https://doi.org/10.4254/wjh.v8.i8.385

[25] Yasunaka, T., Ikeda, F., Wada, N., Morimoto, Y., Fujioka, S., Toshimori, J., et al. (2016) Entecavir Reduces Hepatocarcinogenesis in Chronic Hepatitis B Patients. Acta Medica Okayama, 70, 1-12.

[26] Cho, H., Ahn, H., Lee, D.H., Lee, J.H., Jung, Y.J., Chang, Y., et al. (2018) Entecavir and Tenofovir Reduce Hepatitis B Virus-Related Hepatocellular Carcinoma Recur- 
rence More Effectively than Other Antivirals. Journal of Viral Hepatitis. https://doi.org/10.1111/jvh.12855

[27] Wang, J.P., Kao, F.Y., Wu, C.Y., Hung, Y.P., Chao, Y., Chou, Y.J., et al. (2015) Nucleos(t)ide Analogues Associated with a Reduced Risk of Hepatocellular Carcinoma in Hepatitis B Patients: A Population-Based Cohort Study. Cancer, 121, 1446-1455. https://doi.org/10.1002/cncr.29159

[28] Petruzziello, A., Marigliano, S., Loquercio, G., Cozzolino, A. and Cacciapuoti, C. (2016) Global Epidemiology of Hepatitis C Virus Infection: An Up-Date of the Distribution and Circulation of Hepatitis C Virus Genotypes. World Journal of Gastroenterology, 22, 7824-7840. https://doi.org/10.3748/wjg.v22.i34.7824

[29] Rehermann, B. and Nascimbeni, M. (2005) Immunology of Hepatitis B Virus and Hepatitis C Virus Infection. Nature Reviews Immunology, 5, 215-229. https://doi.org/10.1038/nri1573

[30] El-Serag, H.B. (2011) Hepatocellular Carcinoma. The New England Journal of Medicine, 365, 1118-1127. https://doi.org/10.1056/NEJMra1001683

[31] Wong, R.J., Aguilar, M., Cheung, R., Perumpail, R.B., Harrison, S.A., Younossi, Z.M., et al. (2015) Nonalcoholic Steatohepatitis Is the Second Leading Etiology of Liver Disease among Adults Awaiting Liver Transplantation in the United States. Gastroenterology, 148, 547-555. https://doi.org/10.1053/j.gastro.2014.11.039

[32] Pileri, P., Uematsu, Y., Campagnoli, S., Galli, G., Falugi, F., Petracca, R., et al. (1998) Binding of Hepatitis C Virus to CD81. Science, 282, 938-941.

https://doi.org/10.1126/science.282.5390.938

[33] Sasaki, M., Yamauchi, K., Nakanishi, T., Kamogawa, Y. and Hayashi, N. (2003) In Vitro Binding of Hepatitis C Virus to CD81-Positive and -Negative Human Cell Lines. Journal of Gastroenterology and Hepatology, 18, 74-79. https://doi.org/10.1046/j.1440-1746.2003.02925.x

[34] Meredith, L.W., Wilson, G.K., Fletcher, N.F. and McKeating, J.A. (2012) Hepatitis C Virus Entry: Beyond Receptors. Reviews in Medical Virology, 22, 182-193. https://doi.org/10.1002/rmv.723

[35] Penin, F., Dubuisson, J., Rey, F.A., Moradpour, D. and Pawlotsky, J.M. (2004) Structural Biology of Hepatitis C Virus. Hepatology, 39, 5-19. https://doi.org/10.1002/hep.20032

[36] Lee, Y.A., Wallace, M.C. and Friedman, S.L. (2015) Pathobiology of Liver Fibrosis: A Translational Success Story. Gut, 64, 830-841. https://doi.org/10.1136/gutjnl-2014-306842

[37] Lemon, S.M. and McGivern, D.R. (2012) Is Hepatitis C Virus Carcinogenic? Gastroenterology, 142, 1274-1278. https://doi.org/10.1053/j.gastro.2012.01.045

[38] Barazani, Y., Hiatt, J.R., Tong, M.J. and Busuttil, R.W. (2007) Chronic Viral Hepatitis and Hepatocellular Carcinoma. World Journal of Surgery, 31, 1243-1248. https://doi.org/10.1007/s00268-007-9041-3

[39] Hino, O., Kajino, K., Umeda, T. and Arakawa, Y. (2002) Understanding the Hypercarcinogenic State in Chronic Hepatitis: A Clue to the Prevention of Human Hepatocellular Carcinoma. Journal of Gastroenterology, 37, 883-887. https://doi.org/10.1007/s005350200149

[40] Henderson, N.C., Arnold, T.D., Katamura, Y., Giacomini, M.M., Rodriguez, J.D., McCarty, J.H., et al. (2013) Targeting of ov Integrin Identifies a Core Molecular Pathway That Regulates Fibrosis in Several Organs. Nature Medicine, 19, 1617-1624. https://doi.org/10.1038/nm.3282 
[41] El-Serag, H.B. (2012) Epidemiology of Viral Hepatitis and Hepatocellular Carcinoma. Gastroenterology, 142, 1264-1273. https://doi.org/10.1053/j.gastro.2011.12.061

[42] Davis, G.L., Alter, M.J., El-Serag, H., Poynard, T. and Jennings, L.W. (2010) Aging of Hepatitis C Virus (HCV)-Infected Persons in the United States: A Multiple Cohort Model of HCV Prevalence and Disease Progression. Gastroenterology, 138, 513-521. https://doi.org/10.1053/j.gastro.2009.09.067

[43] Calle, E.E. and Kaaks, R. (2004) Overweight, Obesity and Cancer: Epidemiological Evidence and Proposed Mechanisms. Nature Reviews Cancer, 4, 579-591. https://doi.org/10.1038/nrc1408

[44] Roche, B., Coilly, A., Duclos-Vallee, J.C. and Samuel, D. (2018) The Impact of Treatment of Hepatitis $\mathrm{C}$ with DAAs on the Occurrence of HCC. Liver International, 38, 139-145. https://doi.org/10.1111/liv.13659

[45] Lee, M.H., Yang, H.I., Lu, S.N., Jen, C.L., You, S.L., Wang, L.Y., et al. (2012) Chronic Hepatitis C Virus Infection Increases Mortality from Hepatic and Extrahepatic Diseases: A Community-Based Long-Term Prospective Study. The Journal of Infectious Diseases, 206, 469-477. https://doi.org/10.1093/infdis/jis385

[46] Ioannou, G.N., Green, P.K. and Berry, K. (2017) HCV Eradication Induced by Direct-Acting Antiviral Agents Reduces the Risk of Hepatocellular Carcinoma. Journal of Hepatology.

[47] Colombo, M. and Boccaccio, V. (2018) Hepatitis C Eradication with DAA and Risk of Liver Cancer Recurrence: The Debate Unrests. Journal of Viral Hepatitis.

[48] Conti, F., Buonfiglioli, F., Scuteri, A., Crespi, C., Bolondi, L., Caraceni, P., et al. (2016) Early Occurrence and Recurrence of Hepatocellular Carcinoma in HCV-Related Cirrhosis Treated with Direct-Acting Antivirals. Journal of Hepatology, 65, 727-733. https://doi.org/10.1016/j.jhep.2016.06.015

[49] Grandhe, S. and Frenette, C.T. (2017) Occurrence and Recurrence of Hepatocellular Carcinoma after Successful Direct-Acting Antiviral Therapy for Patients with Chronic Hepatitis C Virus Infection. Gastroenterology \& Hepatology, 13, 421-425.

[50] Kozbial, K., Moser, S., Al-Zoairy, R., Schwarzer, R., Datz, C., Stauber, R., et al. (2017) Follow-Up of Sustained Virological Responders with Hepatitis C and Advanced Liver Disease after Interferon/Ribavirin-Free Treatment. Liver International.

[51] Farazi, P.A. and DePinho, R.A. (2006) Hepatocellular Carcinoma Pathogenesis: From Genes to Environment. Nature Reviews Cancer, 6, 674-687. https://doi.org/10.1038/nrc1934

[52] Lim, S.S., Vos, T., Flaxman, A.D., Danaei, G., Shibuya, K., Adair-Rohani, H., et al. (2012) A Comparative Risk Assessment of Burden of Disease and Injury Attributable to 67 Risk Factors and Risk Factor Clusters in 21 Regions, 1990-2010: A Systematic Analysis for the Global Burden of Disease Study 2010. The Lancet, 380, 2224-2260. https://doi.org/10.1016/S0140-6736(12)61766-8

[53] Galicia-Moreno, M. and Gutierrez-Reyes, G. (2014) The Role of Oxidative Stress in the Development of Alcoholic Liver Disease. Revista de Gastroenterología de México, 79, 135-144. https://doi.org/10.1016/j.rgmx.2014.03.001

[54] Ghouri, Y.A., Mian, I. and Rowe, J.H. (2017) Review of Hepatocellular Carcinoma: Epidemiology, Etiology, and Carcinogenesis. Journal of Carcinogenesis, 16, 1. https://doi.org/10.4103/jcar.JCar_9_16

[55] Hutchinson, S.J., Bird, S.M. and Goldberg, D.J. (2005) Influence of Alcohol on the Progression of Hepatitis C Virus Infection: A Meta-Analysis. Clinical Gastroen- 
terology and Hepatology, 3, 1150-1159.

[56] Magnussen, A. and Parsi, M.A. (2013) Aflatoxins, Hepatocellular Carcinoma and Public Health. World Journal of Gastroenterology, 19, 1508-1512. https://doi.org/10.3748/wjg.v19.i10.1508

[57] Saad-Hussein, A., Taha, M.M., Beshir, S., Shahy, E.M., Shaheen, W. and Elhamshary, M. (2014) Carcinogenic Effects of Aflatoxin B1 among Wheat Handlers. International Journal of Occupational and Environmental Health, 20, 215-219. https://doi.org/10.1179/2049396714Y.0000000069

[58] Kew, M.C. (2013) Aflatoxins as a Cause of Hepatocellular Carcinoma. Journal of Gastrointestinal and Liver Diseases, 22, 305-310.

[59] Qi, L.N., Bai, T., Chen, Z.S., Wu, F.X., Chen, Y.Y., De, X.B., et al. (2015) The p53 Mutation Spectrum in Hepatocellular Carcinoma from Guangxi, China: Role of Chronic Hepatitis B Virus Infection and Aflatoxin B1 Exposure. Liver International, 35, 999-1009. https://doi.org/10.1111/liv.12460

[60] Hamid, A.S., Tesfamariam, I.G., Zhang, Y. and Zhang, Z.G. (2013) Aflatoxin B1-Induced Hepatocellular Carcinoma in Developing Countries: Geographical Distribution, Mechanism of Action and Prevention. Oncology Letters, 5, 1087-1092. https://doi.org/10.3892/ol.2013.1169

[61] Kucukcakan, B. and Hayrulai-Musliu, Z. (2015) Challenging Role of Dietary Aflatoxin B1 Exposure and Hepatitis B Infection on Risk of Hepatocellular Carcinoma. Open Access Macedonian Journal of Medical Sciences, 3, 363-369. https://doi.org/10.3889/oamjms.2015.032

[62] Liu, Y. and Wu, F. (2010) Global Burden of Aflatoxin-Induced Hepatocellular Carcinoma: A Risk Assessment. Environmental Health Perspectives, 118, 818-824.

[63] Bellentani, S., Scaglioni, F., Marino, M. and Bedogni, G. (2010) Epidemiology of Non-Alcoholic Fatty Liver Disease. Digestive Diseases, 28, 155-161. https://doi.org/10.1159/000282080

[64] Said, A. and Ghufran, A. (2017) Epidemic of Non-Alcoholic Fatty Liver Disease and Hepatocellular Carcinoma. World Journal of Clinical Oncology, 8, 429-436. https://doi.org/10.5306/wjco.v8.i6.429

[65] Benedict, M. and Zhang, X. (2017) Non-Alcoholic Fatty Liver Disease: An Expanded Review. World Journal of Hepatology, 9, 715-732. https://doi.org/10.4254/wjh.v9.i16.715

[66] Patel, V., Sanyal, A.J. and Sterling, R. (2016) Clinical Presentation and Patient Evaluation in Nonalcoholic Fatty Liver Disease. Clinical Liver Disease, 20, 277-292. https://doi.org/10.1016/j.cld.2015.10.006

[67] Singh, S., Allen, A.M., Wang, Z., Prokop, L.J., Murad, M.H. and Loomba, R. (2015) Fibrosis Progression in Nonalcoholic Fatty Liver vs Nonalcoholic Steatohepatitis: A Systematic Review and Meta-Analysis of Paired-Biopsy Studies. Clinical Gastroenterology and Hepatology, 13, 643-654. https://doi.org/10.1016/j.cgh.2014.04.014

[68] Welzel, T.M., Graubard, B.I., Zeuzem, S., El-Serag, H.B., Davila, J.A. and McGlynn, K.A. (2011) Metabolic Syndrome Increases the Risk of Primary Liver Cancer in the United States: A Study in the SEER-Medicare Database. Hepatology, 54, 463-471. https://doi.org/10.1002/hep.24397

[69] Marengo, A., Rosso, C. and Bugianesi, E. (2016) Liver Cancer: Connections with Obesity, Fatty Liver, and Cirrhosis. Annual Review of Medicine, 67, 103-117. https://doi.org/10.1146/annurev-med-090514-013832

[70] Chen, G., Ni, Y., Nagata, N., Xu, L. and Ota, T. (2016) Micronutrient Antioxidants 
and Nonalcoholic Fatty Liver Disease. International Journal of Molecular Sciences, 17, 1379. https://doi.org/10.3390/ijms17091379

[71] Angulo, P. (2006) NAFLD, Obesity, and Bariatric Surgery. Gastroenterology, 130, 1848-1852. https://doi.org/10.1053/j.gastro.2006.03.041

[72] Agosti, P., Sabba, C. and Mazzocca, A. (2018) Emerging Metabolic Risk Factors in Hepatocellular Carcinoma and Their Influence on the Liver Microenvironment. Biochimica et Biophysica Acta, 1864, 607-617. https://doi.org/10.1016/j.bbadis.2017.11.026

[73] Siddique, A. and Kowdley, K.V. (2011) Insulin Resistance and Other Metabolic Risk Factors in the Pathogenesis of Hepatocellular Carcinoma. Clinical Liver Disease, 15, 281-296. https://doi.org/10.1016/j.cld.2011.03.007

[74] Hardy, T., Oakley, F., Anstee, Q.M. and Day, C.P. (2016) Nonalcoholic Fatty Liver Disease: Pathogenesis and Disease Spectrum. Annual Review of Pathology, 11, 451-496. https://doi.org/10.1146/annurev-pathol-012615-044224

[75] Ibrahim, S.H., Hirsova, P. and Gores, G.J. (2018) Non-Alcoholic Steatohepatitis Pathogenesis: Sublethal Hepatocyte Injury as a Driver of Liver Inflammation. Gut, 67, 963-972. https://doi.org/10.1136/gutjnl-2017-315691

[76] Hirsova, P., Ibrahim, S.H., Gores, G.J. and Malhi, H. (2016) Lipotoxic Lethal and Sublethal Stress Signaling in Hepatocytes: Relevance to NASH Pathogenesis. The Journal of Lipid Research, 57, 1758-1770. https://doi.org/10.1194/jlr.R066357

[77] Krenkel, O. and Tacke, F. (2017) Liver Macrophages in Tissue Homeostasis and Disease. Nature Reviews Immunology, 17, 306-321. https://doi.org/10.1038/nri.2017.11

[78] Heymann, F. and Tacke, F. (2016) Immunology in the Liver-From Homeostasis to Disease. Nature Reviews Gastroenterology \& Hepatology, 13, 88-110. https://doi.org/10.1038/nrgastro.2015.200

[79] Koyama, Y. and Brenner, D.A. (2017) Liver Inflammation and Fibrosis. Journal of Clinical Investigation, 127, 55-64. https://doi.org/10.1172/JCI88881

[80] Sera, T., Sumii, T., Fujita, R. and Kudo, S. (2018) Effect of Shear Stress on the Migration of Hepatic Stellate Cells. In Vitro Cellular \& Developmental Biology-Animal, 54, 11-22. https://doi.org/10.1007/s11626-017-0202-x

[81] Sanyal, A., Poklepovic, A., Moyneur, E. and Barghout, V. (2010) Population-Based Risk Factors and Resource Utilization for HCC: US Perspective. Current Medical Research and Opinion, 26, 2183-2191. https://doi.org/10.1185/03007995.2010.506375

[82] Yasui, K., Hashimoto, E., Komorizono, Y., Koike, K., Arii, S., Imai, Y., et al. (2011) Characteristics of Patients with Nonalcoholic Steatohepatitis Who Develop Hepatocellular Carcinoma. Clinical Gastroenterology and Hepatology, 9, 428-433. https://doi.org/10.1016/j.cgh.2011.01.023

[83] Bianchini, F., Kaaks, R. and Vainio, H. (2002) Overweight, Obesity, and Cancer Risk. The Lancet Oncology, 3, 565-574. https://doi.org/10.1016/S1470-2045(02)00849-5

[84] Park, E.J., Lee, J.H., Yu, G.Y., He, G., Ali, S.R., Holzer, R.G., et al. (2010) Dietary and Genetic Obesity Promote Liver Inflammation and Tumorigenesis by Enhancing IL-6 and TNF Expression. Cell, 140, 197-208. https://doi.org/10.1016/j.cell.2009.12.052

[85] Calle, E.E., Rodriguez, C., Walker-Thurmond, K. and Thun, M.J. (2003) Overweight, Obesity, and Mortality from Cancer in a Prospectively Studied Cohort of 
U.S. Adults. The New England Journal of Medicine, 348, 1625-1638. https://doi.org/10.1056/NEJMoa021423

[86] Tournier, C. (2013) The 2 Faces of JNK Signaling in Cancer. Genes \& Cancer, 4, 397-400. https://doi.org/10.1177/1947601913486349

[87] Jiang, C.M., Pu, C.W., Hou, Y.H., Chen, Z., Alanazy, M. and Hebbard, L. (2014) Non Alcoholic Steatohepatitis a Precursor for Hepatocellular Carcinoma Development. World Journal of Gastroenterology, 20, 16464-16473. https://doi.org/10.3748/wjg.v20.i44.16464

[88] Schmidt-Arras, D. and Rose-John, S. (2016) IL-6 Pathway in the Liver: From Physiopathology to Therapy. Journal of Hepatology, 64, 1403-1415. https://doi.org/10.1016/j.jhep.2016.02.004

[89] Jiang, N., Sun, R. and Sun, Q. (2014) Leptin Signaling Molecular Actions and Drug Target in Hepatocellular Carcinoma. Drug Design, Development and Therapy, 8, 2295-2302.

[90] Sharma, D., Wang, J., Fu, P.P., Sharma, S., Nagalingam, A., Mells, J., et al. (2010) Adiponectin Antagonizes the Oncogenic Actions of Leptin in Hepatocellular Carcinogenesis. Hepatology, 52, 1713-1722. https://doi.org/10.1002/hep.23892

[91] Meex, R.C.R. and Watt, M.J. (2017) Hepatokines: Linking Nonalcoholic Fatty Liver Disease and Insulin Resistance. Nature Reviews Endocrinology, 13, 509-520. https://doi.org/10.1038/nrendo.2017.56

[92] Maximos, M., Bril, F., Portillo, S.P., Lomonaco, R., Orsak, B., Biernacki, D., et al. (2015) The Role of Liver Fat and Insulin Resistance as Determinants of Plasma Aminotransferase Elevation in Nonalcoholic Fatty Liver Disease. Hepatology, 61, 153-160. https://doi.org/10.1002/hep.27395

[93] Cusi, K. (2016) Treatment of Patients with Type 2 Diabetes and Non-Alcoholic Fatty Liver Disease: Current Approaches and Future Directions. Diabetologia, 59, 1112-1120. https://doi.org/10.1007/s00125-016-3952-1

[94] Starley, B.Q., Calcagno, C.J. and Harrison, S.A. (2010) Nonalcoholic Fatty Liver Disease and Hepatocellular Carcinoma: A Weighty Connection. Hepatology, 51, 1820-1832. https://doi.org/10.1002/hep.23594

[95] Chun, Y.S., Huang, M., Rink, L. and Von Mehren, M. (2014) Expression Levels of Insulin-Like Growth Factors and Receptors in Hepatocellular Carcinoma: A Retrospective Study. World Journal of Surgical Oncology, 12, 231.

https://doi.org/10.1186/1477-7819-12-231

[96] Mouzaki, M., Comelli, E.M., Arendt, B.M., Bonengel, J., Fung, S.K., Fischer, S.E., et al. (2013) Intestinal Microbiota in Patients with Nonalcoholic Fatty Liver Disease. Hepatology, 58, 120-127. https://doi.org/10.1002/hep.26319

[97] Zhu, L., Baker, S.S., Gill, C., Liu, W., Alkhouri, R., Baker, R.D., et al. (2013) Characterization of Gut Microbiomes in Nonalcoholic Steatohepatitis (NASH) Patients: A Connection between Endogenous Alcohol and NASH. Hepatology, 57, 601-609. https://doi.org/10.1002/hep.26093

[98] Schloss, P.D. and Handelsman, J. (2004) Status of the Microbial Census. Microbiology and Molecular Biology Reviews, 68, 686-691. https://doi.org/10.1128/MMBR.68.4.686-691.2004

[99] Vyas, U. and Ranganathan, N. (2012) Probiotics, Prebiotics, and Synbiotics: Gut and Beyond. Gastroenterology Research and Practice, 2012, Article ID: 872716. https://doi.org/10.1155/2012/872716

[100] Koropatkin, N.M., Cameron, E.A. and Martens, E.C. (2012) How Glycan Metabo- 
lism Shapes the Human Gut Microbiota. Nature Reviews Microbiology, 10, 323-335. https://doi.org/10.1038/nrmicro2746

[101] Bull, M.J. and Plummer, N.T. (2014) Part 1: The Human Gut Microbiome in Health and Disease. Integrative Medicine (Encinitas), 13, 17-22.

[102] Vanni, E. and Bugianesi, E. (2009) The Gut-Liver Axis in Nonalcoholic Fatty Liver Disease: Another Pathway to Insulin Resistance? Hepatology, 49, 1790-1792. https://doi.org/10.1002/hep.23036

[103] Sanduzzi, Z.M., Rocco, A., Compare, D. and Nardone, G. (2017) The Gut Microbiota: A New Potential Driving Force in Liver Cirrhosis and Hepatocellular Carcinoma. United European Gastroenterology Journal, 5, 944-953. https://doi.org/10.1177/2050640617705576

[104] Compare, D., Coccoli, P., Rocco, A., Nardone, O.M., De Maria, S., Carteni, M., et al. (2012) Gut-Liver Axis: The Impact of Gut Microbiota on Non Alcoholic Fatty Liver Disease. Nutrition, Metabolism and Cardiovascular Diseases, 22, 471-476. https://doi.org/10.1016/j.numecd.2012.02.007

[105] Zhang, H.Y., Han, D.W., Su, A.R., Zhang, L.T., Zhao, Z.F., Ji, J.Q., et al. (2007) Intestinal Endotoxemia Plays a Central Role in Development of Hepatopulmonary Syndrome in a Cirrhotic Rat Model Induced by Multiple Pathogenic Factors. World Journal of Gastroenterology, 13, 6385-6395. https://doi.org/10.3748/wjg.v13.i47.6385

[106] Ruiz, A.G., Casafont, F., Crespo, J., Cayon, A., Mayorga, M., Estebanez, A., et al. (2007) Lipopolysaccharide-Binding Protein Plasma Levels and Liver TNF-Alpha Gene Expression in Obese Patients: Evidence for the Potential Role of Endotoxin in the Pathogenesis of Non-Alcoholic Steatohepatitis. Obesity Surgery, 17, 1374-1380. https://doi.org/10.1007/s11695-007-9243-7

[107] Borrelli, A., Bonelli, P., Tuccillo, F.M., Goldfine, I.D., Evans, J.L., Buonaguro, F.M., et al. (2018) Role of Gut Microbiota and Oxidative Stress in the Progression of Non-Alcoholic Fatty Liver Disease to Hepatocarcinoma: Current and Innovative Therapeutic Approaches. Redox Biology, 15, 467-479. https://doi.org/10.1016/j.redox.2018.01.009

[108] Seko, Y., Sumida, Y., Tanaka, S., Mori, K., Taketani, H., Ishiba, H., et al. (2017) Development of Hepatocellular Carcinoma in Japanese Patients with Biopsy-Proven Non-Alcoholic Fatty Liver Disease: Association between PNPLA3 Genotype and Hepatocarcinogenesis/Fibrosis Progression. Hepatology Research, 47, 1083-1092. https://doi.org/10.1111/hepr.12840

[109] Romeo, S., Kozlitina, J., Xing, C., Pertsemlidis, A., Cox, D., Pennacchio, L.A., et al. (2008) Genetic Variation in PNPLA3 Confers Susceptibility to Nonalcoholic Fatty Liver Disease. Nature Genetics, 40, 1461-1465. https://doi.org/10.1038/ng.257

[110] Pirazzi, C., Valenti, L., Motta, B.M., Pingitore, P., Hedfalk, K., Mancina, R.M., et al. (2014) PNPLA3 Has Retinyl-Palmitate Lipase Activity in Human Hepatic Stellate Cells. Human Molecular Genetics, 23, 4077-4085. https://doi.org/10.1093/hmg/ddu121

[111] Huang, Y., Cohen, J.C. and Hobbs, H.H. (2011) Expression and Characterization of a PNPLA3 Protein Isoform (I148M) Associated with Nonalcoholic Fatty Liver Disease. The Journal of Biological Chemistry, 286, 37085-37093. https://doi.org/10.1074/jbc.M111.290114

[112] Pingitore, P., Pirazzi, C., Mancina, R.M., Motta, B.M., Indiveri, C., Pujia, A., et al. (2014) Recombinant PNPLA3 Protein Shows Triglyceride Hydrolase Activity and Its I148M Mutation Results in Loss of Function. Biochimica et Biophysica Acta, 
1841, 574-580. https://doi.org/10.1016/j.bbalip.2013.12.006

[113] Pirazzi, C., Adiels, M., Burza, M.A., Mancina, R.M., Levin, M., Stahlman, M., et al. (2012) Patatin-Like Phospholipase Domain-Containing 3 (PNPLA3) I148M (rs738409) Affects Hepatic VLDL Secretion in Humans and in Vitro. Journal of Hepatology, 57, 1276-1282. https://doi.org/10.1016/j.jhep.2012.07.030

[114] Fields, A.L., Soprano, D.R. and Soprano, K.J. (2007) Retinoids in Biological Control and Cancer. Journal of Cellular Biochemistry, 102, 886-898. https://doi.org/10.1002/jcb.21530

[115] Sookoian, S., Castano, G.O. and Pirola, C.J. (2015) PNPLA3 I148M Variant Is Associated with Metabolic Stress-Response Phenotype in Patients with Nonalcoholic Fatty Liver Disease. Hepatology, 61, 1769. https://doi.org/10.1002/hep.27390

[116] Streba, L.A., Vere, C.C., Rogoveanu, I. and Streba, C.T. (2015) Nonalcoholic Fatty Liver Disease, Metabolic Risk Factors, and Hepatocellular Carcinoma: An Open Question. World Journal of Gastroenterology, 21, 4103-4110. https://doi.org/10.3748/wjg.v21.i14.4103

[117] Tsuchiya, N., Sawada, Y., Endo, I., Saito, K., Uemura, Y. and Nakatsura, T. (2015) Biomarkers for the Early Diagnosis of Hepatocellular Carcinoma. World Journal of Gastroenterology, 21, 10573-10583. https://doi.org/10.3748/wjg.v21.i37.10573

[118] Bruix, J. and Sherman, M. (2011) Management of Hepatocellular Carcinoma: An Update. Hepatology, 53, 1020-1022. https://doi.org/10.1002/hep.24199

[119] European Association for the Study of The Liver, European Organisation for Research and Treatment of Cancer (2012) EASL-EORTC Clinical Practice Guidelines: Management of Hepatocellular Carcinoma. Journal of Hepatology, 56, 908-943. https://doi.org/10.1016/j.jhep.2011.12.001

[120] Chan, S.L., Mo, F.K., Johnson, P.J., Hui, E.P., Ma, B.B., Ho, W.M., et al. (2009) New Utility of an Old Marker: Serial Alpha-Fetoprotein Measurement in Predicting Radiologic Response and Survival of Patients with Hepatocellular Carcinoma Undergoing Systemic Chemotherapy. Journal of Clinical Oncology, 27, 446-452. https://doi.org/10.1200/JCO.2008.18.8151

[121] de Lope, C.R., Tremosini, S., Forner, A., Reig, M. and Bruix, J. (2012) Management of HCC. Journal of Hepatology, 56, S75-S87. https://doi.org/10.1016/S0168-8278(12)60009-9

[122] Omata, M., Cheng, A.L., Kokudo, N., Kudo, M., Lee, J.M., Jia, J., et al. (2017) Asia-Pacific Clinical Practice Guidelines on the Management of Hepatocellular Carcinoma: A 2017 Update. Hepatology International, 11, 317-370. https://doi.org/10.1007/s12072-017-9799-9

[123] Carr, B.I., Guerra, V., Giannini, E.G., Farinati, F., Ciccarese, F., Rapaccini, G.L., et al. (2014) Low Alpha-Fetoprotein HCC and the Role of GGTP. The International Journal of Biological Markers, 29, e395-e402. https://doi.org/10.5301/jbm.5000092

[124] Mita, Y., Aoyagi, Y., Yanagi, M., Suda, T., Suzuki, Y. and Asakura, H. (1998) The Usefulness of Determining Des-Gamma-Carboxy Prothrombin by Sensitive Enzyme Immunoassay in the Early Diagnosis of Patients with Hepatocellular Carcinoma. Cancer, 82, 1643-1648. https://doi.org/10.1002/(SICI)1097-0142(19980501)82:9<1643::AID-CNCR8>3.0.C $\mathrm{O} ; 2-\mathrm{B}$

[125] Okuda, H., Nakanishi, T., Takatsu, K., Saito, A., Hayashi, N., Watanabe, K., et al. (1999) Measurement of Serum Levels of Des-Gamma-Carboxy Prothrombin in Patients with Hepatocellular Carcinoma by a Revised Enzyme Immunoassay Kit with 
Increased Sensitivity. Cancer, 85, 812-818.

https://doi.org/10.1002/(SICI)1097-0142(19990215)85:4<812::AID-CNCR8>3.0.CO; $\underline{2-\mathrm{O}}$

[126] Higashi, T., Hasegawa, K., Kokudo, N., Makuuchi, M., Izumi, N., Ichida, T., et al. (2011) Demonstration of Quality of Care Measurement Using the Japanese Liver Cancer Registry. Hepatology Research, 41, 1208-1215.

https://doi.org/10.1111/j.1872-034X.2011.00880.x

[127] Yu, R., Tan, Z., Xiang, X., Dan, Y. and Deng, G. (2017) Effectiveness of PIVKA-II in the Detection of Hepatocellular Carcinoma Based on Real-World Clinical Data. BMC Cancer, 17, 608. https://doi.org/10.1186/s12885-017-3609-6

[128] Saitta, C., Raffa, G., Alibrandi, A., Brancatelli, S., Lombardo, D., Tripodi, G., et al. (2017) PIVKA-II Is a Useful Tool for Diagnostic Characterization of Ultrasound-Detected Liver Nodules in Cirrhotic Patients. Medicine (Baltimore), 96, e7266. https://doi.org/10.1097/MD.0000000000007266 